\title{
Ambient temperature affects mechanosensory host location in a parasitic wasp
}

\section{Journal Article}

Author(s):

Samietz, J.; Kroder, S.; Schneider, D.; Dorn, S.

Publication date:

2006-02

Permanent link:

https://doi.org/10.3929/ethz-b-000001203

Rights / license:

In Copyright - Non-Commercial Use Permitted

Originally published in:

Journal of Comparative Physiology A 192(2), https://doi.org/10.1007/s00359-005-0057-6 


\section{Ambient temperature affects mechanosensory host location in a parasitic wasp}

Received: 22 April 2005/ Revised: 30 August 2005/ Accepted: 3 September 2005/Published online: 30 November 2005

(C) Springer-Verlag 2005

\begin{abstract}
Certain parasitic wasps (Ichneumonidae, Pimplinae) use self-produced vibrations transmitted on plant substrate to locate their immobile concealed hosts (i.e. lepidopteran pupae). This mechanosensory mechanism, called the vibrational sounding, depends both on physical cues of the environment and physical activity of the parasitoid and is postulated to depend on ambient temperature. We analysed the influences of temperature on vibrational sounding by choice experiments using plant-stem models with hidden host mimics in the temperate species Pimpla turionellae. The results show a significant effect of temperature on host-location activity and on the success of this process. Outside an optimum range, the performance of the wasps decreased both at low and high temperatures. Below $10^{\circ} \mathrm{C}$ and beyond $24^{\circ} \mathrm{C}$, the wasps displayed (1) substantial reduction in responsiveness, i.e. proportion of females showing ovipositor insertions, (2) reduction of quantitative activity with ovipositor insertions in the individuals, and (3) reduced precision of mechanosensory host location. Nevertheless, female wasps were able to locate their host over a surprisingly broad range of ambient temperatures which indicates that the wasps are able to compensate for temperature effects on vibrational sounding.
\end{abstract}

Keywords Echolocation · Host location Parasitoid $\cdot$ Temperature $\cdot$ Vibration

J. Samietz $\cdot$ S. Kroder $\cdot$ D. Schneider $\cdot$ S. Dorn

Applied Entomology, Swiss Federal Institute of Technology

(ETH) Zurich, Institute of Plant Sciences, Zurich, Switzerland

Present address: J. Samietz $(\square)$

Agroscope FAW Wädenswil, Swiss Federal Research Station for Horticulture, PO Box 185, 8820 Wädenswil, Schloss, Switzerland E-mail: joerg.samietz@faw.admin.ch

Tel.: + 41-44-7836193

Fax: +41-44-7836434

\section{Introduction}

Temperature is one of the most important environmental parameters influencing all organisms. Although thermal conditions affect nearly all biological processes, rates and functions (Willmer et al. 2000), there are relatively few studies dealing with the influence of temperature on sensory mechanisms during species interactions. Most of this work is restricted to the influence of temperature on the interaction between plants and the herbivores (e.g. Alonso 1999; Bale et al. 2002; Hughes et al. 2004; Kührt et al. 2005). Few studies are dealing with parasitoid-host interactions but are restricted to temperature effects on emission of potential behaviourally effective plant volatiles (Gouinguené and Turlings 2002; Vallat et al. 2005), on the attractiveness of volatiles per se (Reddy et al. 2002) or on parasitation rates (e.g. Benrey and Denno 1997; Flinn 1998). How temperature effects relate to the sensory process of host location itself is mostly unknown. Accordingly, the importance of certain host location mechanisms in parasitoids under different temperature conditions is difficult to understand yet.

Parasitoids of concealed pupae depend heavily on physical cues as indicators of their hosts' whereabouts. Certain species of the Pimplinae (Hymenoptera, Ichneumonidae) have developed a strategy very similar to echolocation to locate their pupal hosts within the plant substrate or hidden in leaf rolls. They use self-produced vibrations transmitted by the antennae on plant parts to sense their immobile hosts (lepidopteran pupae) by signal modification received with the subgenual organ (Wäckers et al. 1998; Otten et al. 2002). This mechanosensory mechanism, termed vibrational sounding, depends both on physical cues of the environment and physical activity of the parasitoid (Fischer et al. 2001, 2003, 2004; Otten et al. 2002), and should therefore be related to ambient temperature: Since production of the vibrations during mechanosensory orientation is presumed to be of myogenic origin (Henaut 1990; Otten 
et al. 2002; H. Otten et al. unpublished) and the efficiency of mechanoreceptors is usually thermally influenced (e.g. Coro et al. 1994; Hoger and French 1999; Franz and Ronacher 2002), the host location mechanism could be highly susceptible to changes of the wasps' body temperatures and changing ambient temperatures of the presumably ectothermic insects. It is to expect that the parasitoid females have a distinct temperature range according to the thermal conditions of their natural habitat in which they respond positively with host location by vibrational sounding. Within such an optimum range, they should show high activity of ovipositor insertions towards the host which should decline if the temperatures rise too high or fall too low. This also suggests that the precision of host location by vibrational sounding may decline outside optimum temperatures.

In this study, the possible influences of temperature on mechanosensory host location was analysed in the temperate wasp Pimpla turionellae (L.) (Hymenoptera, Ichneumonidae, Pimplinae). This polyphagous parasitoid of lepidopteran pupae has been well investigated with respect to the use of vibrational sounding as a host location mechanism (Wäckers et al. 1998; Otten et al. 2002; Fischer et al. 2001) and with respect to physical environmental factors of the environment influencing the performance of this mechanism (Fischer et al. 2003). The temperate distribution of the species suggests a relatively wide range of ambient conditions, the species has to deal with and it facilitates testing for performance during vibrational sounding from below $10^{\circ} \mathrm{C}$ to beyond $30^{\circ} \mathrm{C}$. We tested the hypothesis of thermal influence of mechanosensory host location by choice experiments in the laboratory using plant-stem models with hidden host mimics. Such models elicit a behavioural response of the wasps which is comparable to host location in the natural system (Fischer et al. 2004) while excluding chemical and visual stimuli and therefore focusing solely on mechanosensory cues.

\section{Materials and methods}

\section{Parasitoid rearing}

A laboratory strain of $P$. turionellae was reared on pupae of the wax moth Galleria mellonella $\mathrm{L}$. Adults were kept in Plexiglas containers $\left(25 \times 25 \times 25 \mathrm{~cm}^{3}\right)$ at $15^{\circ} \mathrm{C}$ and $70 \%$ relative humidity $(\mathrm{RH})$ in a climate chamber (Conviron, PGV72, Winnipeg, Canada) with a photoperiod of $16 \mathrm{~h} / 8 \mathrm{~h}$ :light/darkness. Wasps were fed with honey and water and are allowed to mate. Starting at an age of 5-7 days in P. turionellae, parasitoid females were provided with host pupae for oviposition and hostfeeding three times a week. After having been exposed to the wasps for 3-5 h, parasitised pupae were stored at $24^{\circ} \mathrm{C}, 60 \% \mathrm{RH}$ and a photoperiod of $16 / 8$ :light/darkness until emergence of adults, typically after 3 weeks. Female $P$. turionellae have a lifespan of 1-3 months. The strain of $P$. turionellae was obtained in 1994 from the Forest Research Institute of Baden-Württemberg, Germany.

\section{Plant-stem model}

Females of $P$. turionellae innately attempt to insert their ovipositors into various hollow rounded substrates due to their hosts' shelter inside of cocoons or leaf rolls. Paper cylinders containing a solid section imitating a plant stem with host pupa are therefore ideal experimental models and were used in a number of studies on host location in these insects (e.g. Wäckers et al. 1998; Otten et al. 2001; Fischer et al. 2001, 2003, 2004). In the present study, the plant-stem model was made of a hollow white cylinder (125 mm length; $8 \mathrm{~mm}$ diameter) made of airmail paper (ELCO, Atlantic Clipper Air Mail, $45 \mathrm{~g} \mathrm{~m}^{-2}$, Allschwil, Switzerland). The mechanosensory cue of the host mimic was be provided by a cigarette filter $(15 \times 8 \mathrm{~mm}$, Gizeh, Gummersbach, Germany) hidden inside the paper cylinder. In this way, only mechanosensory cues are offered to the wasps, excluding chemical and visual stimuli on the model. Directed orientation with respect to the host mimic can therefore be attributed exclusively to vibrational sounding. This set up enables testing the responsiveness of the female parasitoids (i.e. the proportion of females inserting their ovipositor into the plant-stem model with the host mimic), the quantitative insertion activity by scoring the number of ovipositor penetrations, and the precision of host location by recording the position of insertions on the model in relation to the host mimic.

\section{Experimental design}

The tested females were at least 1-week old since emergence. Covered pupae were offered to the parasitoids for the first time 24-48 h before the experiments started. At least $1 \mathrm{~h}$ before the experiments animals were acclimatised to the ambient temperature of the according treatment. During the trials, single female parasitoids were placed individually into Plexiglas containers $\left(18.5 \times 8.5 \times 7.5 \mathrm{~cm}^{3}\right)$ and exposed to one host model for a period of $20 \mathrm{~min}$. The experiments were performed individually in a climate chamber (Conviron, PGV72, Winnipeg, Canada) under high frequency white fluorescent light $\left(10 \mathrm{kLux}, 20 \mathrm{~W} \mathrm{~m}^{-2}\right)$ at $60 \% \mathrm{RH}$ and the respective temperature treatment. All parasitoids were used for one trial session only. The stem model was attached to the white background and renewed in each trial. At the end of a trial the individuals were weighed with a high precision balance (Mettler Toledo MT 5, Göttingen, Germany; accuracy $\pm 0.01 \mathrm{mg}$ ).

Twelve temperature treatments with positive response of the wasps were applied in which 558 females were tested. The treatments were set from 6 to $24^{\circ} \mathrm{C}$ in $2^{\circ} \mathrm{C}$ increments, and at 28 and $32^{\circ} \mathrm{C}$. Outside this range at 4 
and $34^{\circ} \mathrm{C}$ no wasp showed a positive response with oviposition activity. The desired sample size for the treatments was at least 20 responding females, i.e. females that inserted their ovipositor at least once into the model during the trial period. At 10 and $20^{\circ} \mathrm{C}$ the sample size was increased to 30 responding females. The responsiveness at $6^{\circ} \mathrm{C}$ ( 30 females tested) and $32^{\circ} \mathrm{C}$ ( 36 females tested) was too low to reach the desired sample size. These two temperature treatments were therefore excluded from factorial analysis of quantitative insertion activity and precision of host location (cf. Data analysis).

\section{Data analysis}

The performance during host location was quantified by scoring the location and precision of ovipositor insertions on the stem-model in relation to the hidden host mimic. For the analysis, each stem-model was subdivided into 34 sections (section width: $3.7 \mathrm{~mm}$ ). Host mimics were located in the 20th to 23 rd sections.

Across the temperature treatments, the responsiveness of the species was analysed as the proportion of females inserting their ovipositor at least once into the stem-model. Quantitative insertion activity was analysed as the average number of ovipositor penetrations per responding female. Finally, the precision of insertions were compared between the temperature treatments by two parameters. First, absolute mean deviation of insertions from the cue centre (bias) for each responding female was calculated as the absolute value of the average insertions' deviation from the cues centre. Second, the variance of the insertion positions (scattering) was calculated for each female.

Differences in the general responsiveness of the females in the different treatments, i.e. the number of individuals inserting their ovipositor versus the inactive ones, were analysed using $\chi^{2}$-test. Quantitative insertion activity and the precision parameters were examined by analyses of variance (ANOVA). To test for a possible influence of body weight on the precision, the distribution of ovipositor insertions on the model was additionally assessed by an analysis of covariance (ANCOVA) with factor temperature and covariate body weight of the individual wasp. Posthoc-pairwise comparisons were performed using Fisher's protected least square difference tests (Fisher's PLSD) on the $5 \%$-significance level.

\section{Results}

\section{Responsiveness}

Over all treatments $40.0 \%$ of the tested female $P$. turionellae responded positively to the plant-stem models with host mimic by ovipositor insertion. The temperature treatments with positive response ranged from 6 to $32^{\circ} \mathrm{C}$ (Fig. 1). At 4 and $34^{\circ} \mathrm{C}$ no wasp showed any insertion of the ovipositor. Within the range of positive response, ambient temperature had a highly significant influence on responsiveness of the females $\left(\chi^{2}\right.$-test, $\chi^{2}=79.9$, d.f. $\left.=11, P<0.0001\right)$. At $18^{\circ} \mathrm{C}$, wasps had the highest responsiveness with $69.0 \%$ of the tested females showing ovipositor insertions. Towards the low and high ends of the temperature range the responsiveness decreased to the lowest values at $6^{\circ} \mathrm{C}(13.3 \%$ response $)$ and $32^{\circ} \mathrm{C}(13.9 \%$ response), respectively (Fig. 1).

\section{Quantitative insertion activity}

In the responding females, absolute numbers of ovipositor insertions were significantly influenced by the temperature treatment (ANOVA, $F_{9,209}=4.58, P<0.0001$ ). The highest average value was reached at $20^{\circ} \mathrm{C}$ with $7.40 \pm 0.84$ insertions (mean $\pm \mathrm{SE}$ ). Towards the lowest and highest temperature with positive response, the activity decreased to $1.60 \pm 0.80$ insertions at $6^{\circ} \mathrm{C}$ and $1.80 \pm 0.58$ insertions at $32^{\circ} \mathrm{C}$ (Fig. 2). Pairwise comparisons revealed a homogeneous group of average ovipositor insertions between 8 and $18^{\circ} \mathrm{C}$ without significant differences among each other (Fisher's PLSD, 5\% significance level). The high averages at 20 and $24^{\circ} \mathrm{C}$ both as the low average at $28^{\circ} \mathrm{C}$ contrast significantly to this latter homogeneous group between 8 and $18^{\circ} \mathrm{C}$ (Fisher's PLSD, 5\% significance level) (Fig. 2).

\section{Precision of host location}

The distribution of ovipositor insertions on the plantstem models was strongly influenced by the temperature treatment but not by the body weight of the wasps (ANCOVA; factor temperature: $F_{9,209}=4.63$, $P<0.0001$; covariate body weight: $F_{1,209}=0.038$, $P=0.847$ ). Factor temperature did not reveal an interaction with the covariate body weight which indicates that the body weight of the female wasps does not modify the temperature influence (ANCOVA, interaction, $F_{9,209}=1.33, P=0.224$ ).

Quantified as the absolute mean deviation of individual ovipositor insertions from the cue centre, the bias of mechanosensory host location was significantly influenced by the temperature treatment (ANOVA, $\left.F_{9,210}=4.54, P<0.0001\right)$. The lowest average bias was found at $20^{\circ} \mathrm{C}$ with $1.19 \pm 0.17$ section widths (mean $\pm \mathrm{SE}$ ). Towards the lowest and highest temperatures analysed, the bias of mechanosensory host location increased to $3.47 \pm 0.77$ section widths at $8^{\circ} \mathrm{C}$ and $4.23 \pm 0.88$ section widths at $28^{\circ} \mathrm{C}$ (Fig. 3a). Pairwise comparisons revealed a homogeneous group of low average bias between 10 and $24^{\circ} \mathrm{C}$ without significant differences among each other (Fisher's PLSD, 5\% significance level). The high average biases of host location at 8 and $28^{\circ} \mathrm{C}$ contrast significantly to this group (Fisher's PLSD, 5\% significance level) and at the same time do not differ from each other (Fig. 3a). 
Fig. 1 Responsiveness of Pimpla turionellae during mechanosensory host location on plant-stem models across temperature treatments from 4 to $34^{\circ} \mathrm{C}$. Responsiveness is quantified as the proportion of females with at least one ovipositor insertion
Fig. 2 Quantitative insertion activity of $P$. turionellae wasps during mechanosensory host location on plant-stem models across the temperature treatments (mean number of ovipositor insertions per responding female $\pm \mathrm{SE}$ ) Different letters indicate significant differences in posthoc analysis (Fisher's PLSD, $P<0.05)$ of the samples included in the ANOVA (grey boxes)
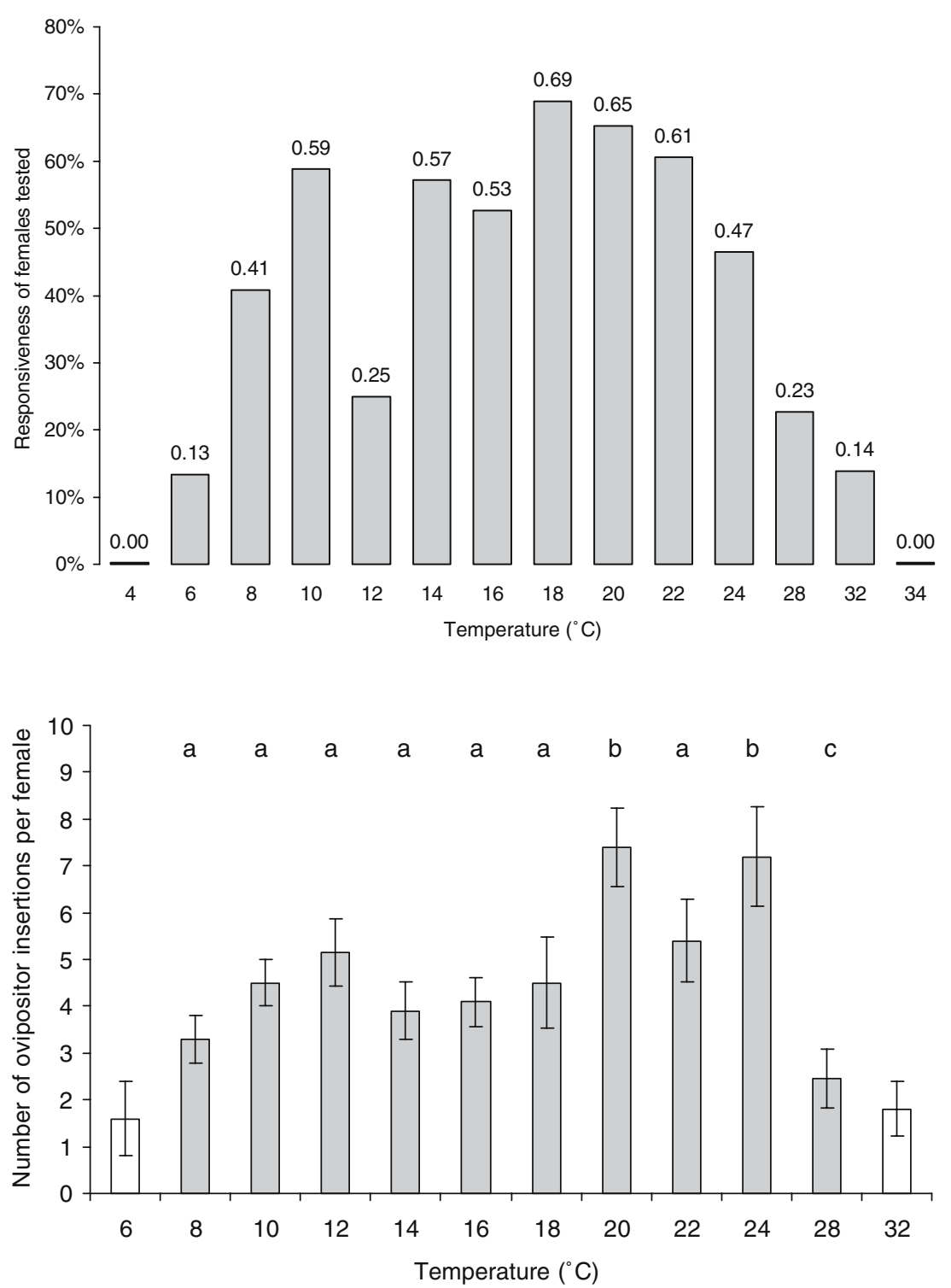

The scattering of mechanosensory host location (i.e. the variance of individual ovipositor insertions on the model) was also significantly influenced by the temperature treatment (ANOVA, $F_{9,166}=6.45, P<0.0001$ ). Lowest scattering occurred at $16^{\circ} \mathrm{C}$ with $9.58 \pm 4.51$ section widths (mean $\pm \mathrm{SE}$ ). Similarly low values of scattering were found in all treatments between 12 and $20^{\circ} \mathrm{C}$ (Fig. 3b). Towards the lowest and highest temperatures analysed, the scattering of mechanosensory host location increased to $17.42 \pm 5.31$ section widths at $8^{\circ} \mathrm{C}$ and $20.23 \pm 7.24$ section widths at $28^{\circ} \mathrm{C}$ (Fig. 3 b).

\section{Discussion}

The results of this study reveal a clear influence of ambient temperature (1) on the positive response during mechanosensory host location, i.e. the proportion of females inserting the ovipositor into the model with host mimic, (2) on the quantitative oviposition activity of the females, and (3) on the precision of vibrational sounding as host location mechanism in the parasitic wasps. Nevertheless, the temperate species studied is able to maintain a high and constant performance of vibrational sounding over a surprisingly broad range of ambient temperatures.

Both responsiveness and quantitative oviposition activity of $P$. turionellae show an optimum around 18$20^{\circ} \mathrm{C}$ with decrease to lower and higher temperatures. These optima correspond roughly to the average temperature during the growing season in the temperate habitats of $P$. turionellae (Bogenschütz 1978). At very low and very high temperatures of the range studied, responsiveness and the number of ovipositior insertions decline drastically. Below $6^{\circ} \mathrm{C}$ and beyond $32^{\circ} \mathrm{C}$ no response to the host mimic can be ascertained. Temperature limits for the sensory system are reflected by the drastically decreasing precision of ovipositor insertions 
Fig. 3 Precision of mechanosensory host location of $P$. turionellae wasps on plantstem models across the temperature treatments: Bias (a) quantified as the absolute mean deviation of individual insertions from the centre of the host mimic (expected value at 21.5 section widths); Scattering (b) as the individual variance of the insertions' positions. Different letters indicate significant differences in posthoc analysis (Fisher's PLSD, $P<0.05)$
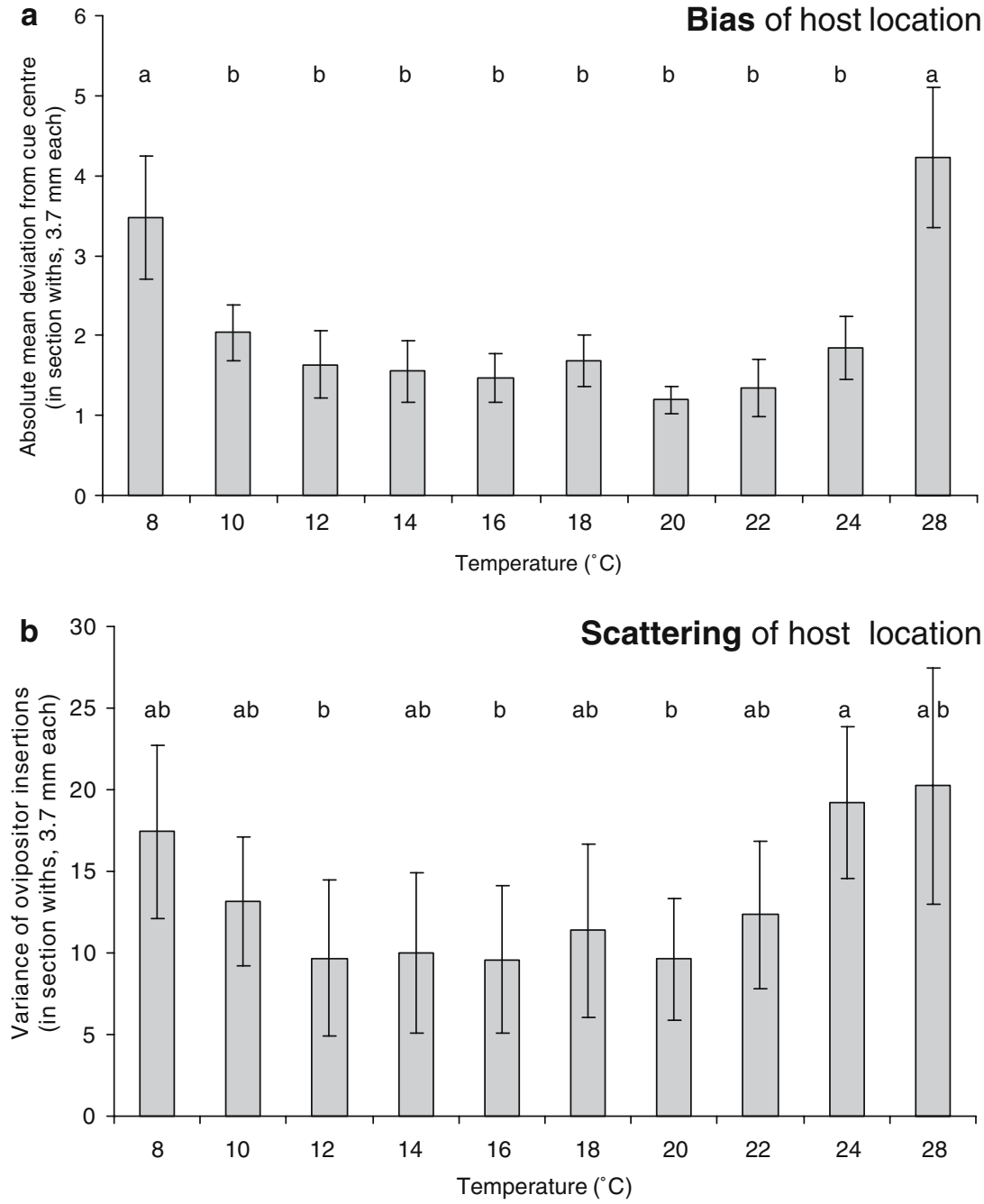

both at the low and high limits of the temperature range with positive response to the host mimic. Both bias of the host location mechanism and scattering of individual ovipositor insertions increase significantly below $10^{\circ} \mathrm{C}$ and at and above $24^{\circ} \mathrm{C}$, respectively. These results match our expectations that the quality of the sensory system declines outside an optimum temperature range to which the species is adapted. However, within a remarkably broad range of temperatures there is hardly any influence on the precision of host location. The bias of the mechanism is constantly low from 10 to $24^{\circ} \mathrm{C}$. Prerequisites for such high precision of the sensory system is the ability to produce, receive, and compute signals for reasonably balanced orientation by vibrational sounding.

Hitherto little is known about the temperature influence on production and computation of vibratory signals in other arthropods. In spiders, higher ambient temperatures result in decreasing values of temporal parameters of substrate borne vibrations for intraspecific communication. However, there are also temperature-invariant parameters such as the duty cycle (Shimizu and Barth 1996). Thoracic vibrations in Melipona bees correspond with the energetic status of the individual (Hrncir et al. 2004a, b). Therefore, they may well also depend on ambient temperature but, to our knowledge, the latter has not as yet been investigated. Physically similar acoustical signals controlled by the neuromuscular system in arthropods are strongly influenced by ambient temperature especially in ectotherms (Gerhardt and Huber 2002; Ryan and Kime 2002). Higher body temperatures elevate the muscle contraction rates and allow faster oscillation of the muscles that generate the sound and hence produce higher frequencies (Greenfield 2002). Myogenic sound production of crickets (Doherty 1985; Martin et al. 2000; Hedrick et al. 2002) and cicadas (Sanborn and Mate 2000; Fonseca and Revez 2002), as well as the production of substrate borne vibrations in spiders (Shimizu and Barth 1996) are subject to temperature dependence. The temperature ranges for sound production in insect species can be consequently quite small. Sub-tropical Diceroprocta olympusa cicadas sing at body temperatures within a range of just about $5^{\circ} \mathrm{C}$ above $35^{\circ} \mathrm{C}$ (Sanborn and Mate 2000). In the temperate cricket Gryllus integer about $95 \%$ of males sing at habitat temperatures between 21 and $28^{\circ} \mathrm{C}$ (Hedrick et al. 2002). 
On the basis of their temperature dependence, the evolution of narrow ranges of males' song parameters through sexual selection can be attributed to stabilizing preference functions in females (Ritchie et al. 2001). Additionally to the signal production, in vibrational sounding, also the mechanoreceptor on the receiving side of the sensory system, the subgenual organ (Otten et al. 2002), is most likely influenced by temperature. For arthropod mechanoreceptors, several studies report a thermal effect on mechanotransduction, action potential encoding, and action potential conduction (e.g. French 1985; Hoger and French 1999; Franz and Ronacher 2002).

Even though we can confidently state thermal effects both at the signal production side and on the reception side, the female wasps seem to deal efficiently with a wide range of changing temperatures during vibrational sounding. One possible explanation to achieve such performance with respect to temperature-variant vibration parameters could be temperature coupling between signal production and reception as known for acoustic communication during cricket- and grasshopper mate finding (Bauer and von Helversen 1987; Pires and Hoy 1992). A second explanation for the discrepancy between the expected temperature effect on vibration and the observed performance of the wasps might be the regulation of the body temperature permitting a correct functioning of vibrational sounding. In bees, e.g. thoracic temperature is increased and well regulated by endothermic heat production with flight muscles (Esch and Goller 1991; Heinrich 1993; Hosler et al. 2000; Stabentheiner et al. 2003). Whether or not the wasps studied here are able to alter their thoracic temperature by endothermy remains to be tested. Yet the results of this study improve our understanding of how temperature acts as a key environmental factor influencing the sensory physiology during species interactions and also contribute to the yet sparse information about the mechanism of vibrational sounding. In future studies, first, the vibratory signals should be investigated with respect to time- and frequency patterns under different temperature conditions, and second, the body temperatures of the wasps should be monitored during mechanosensory host location both at the limits as in the thermal optimum for vibrational sounding.

Acknowledgements We are grateful to Brion Duffy, Friedrich Barth, Anton Stabentheiner and the anonymous referees for valuable comments on earlier drafts of the paper. This work complies with the current laws of Switzerland where the experiments were carried out.

\section{References}

Alonso C (1999) Variation in herbivory by Yponomeuta mahalebella on its only host plant Prunus mahaleb along an elevational gradient. Ecol Entomol 24:371-379

Bale JS, Masters GJ, Hodkinson ID, Awmack C, Bezemer M, Brown VK, Butterfield J, Buse A, Coulson JC, Farrar J, Good JEG, Harrington R, Hartley SE, Jones TH, Lindroth
RL, Press MC, Symrnioudis I, Watt AD, Whittaker JB (2002) Herbivory in global climate change research: Direct effects of rising temperatures on insect herbivores. Glob Change Biol 8:1-16

Bauer M, von Helversen O (1987) Separate localization of sound recognizing and sound producing neural mechanisms in a grasshopper. J Comp Physiol A 161:95-101

Benrey B, Denno RF (1997) The slow-growth-high-mortality hypothesis: A test using the cabbage butterfly. Ecology 78:987999

Bogenschütz H (1978) Fortpflanzung der Schlupfwespe Coccygomimus turionellae (Ichneumonidae). Pub wiss Film Sek Biol Ser 11:1-14

Coro F, Perez M, Machado A (1994) Effects of temperature on a moth auditory receptor. J Comp Physiol A 174:517-525

Doherty JA (1985) Temperature coupling and trade-off phenomena in the acoustic communication-system of the cricket, Gryllus bimaculatus De Geer (Gryllidae). J Exp Biol 114:17-35

Esch H, Goller F (1991) Neural control of fibrillar muscles in bees during shivering and flight. J Exp Biol 159:419-431

Fischer S, Samietz J, Dorn S (2003) Efficiency of vibrational sounding in parasitoid host location depends on substrate density. J Comp Physiol A 189:723-730

Fischer S, Samietz J, Dorn S (2004) Host location of a pupal parasitoid in a tritrophic system compared to a model offering mechanosensory cues only. J Insect Behav 17:191-199

Fischer S, Samietz J, Wäckers FL, Dorn S (2001) Interaction of vibrational and visual cues in parasitoid host location. J Comp Physiol A 187:785-791

Flinn PW (1998) Temperature effects on efficacy of Choetospila elegans (Hymenoptera: Pteromalidae) to suppress Rhyzopertha dominica (Coleoptera: Bostrichidae) in stored wheat. J Econ Entomol 91:320-323

Fonseca PJ, Revez MA (2002) Temperature dependence of cicada songs (Homoptera, Cicadoidea). J Comp Physiol A 187:971976

Franz A, Ronacher B (2002) Temperature dependence of temporal resolution in an insect nervous system. J Comp Physiol A 188:261-271

French AS (1985) The effects of temperature on action-potential encoding in the cockroach tactile spine. J Comp Physiol A $156: 817-821$

Gerhardt HC, Huber F (2002) Acoustic communication in insects and anurans - common problems and diverse solutions. University of Chicago Press, Chicago

Greenfield MD (2002) Signalers and receivers-mechanisms and evolution of arthropod communication. Oxford University Press, Oxford

Gouinguené SP, Turlings TCJ (2002) The effects of abiotic factors on induced volatile emissions in corn plants. Plant Physiol 129:1296-1307

Hedrick AV, Perez D, Lichti N, Yew J (2002) Temperature preferences of male field crickets (Gryllus integer) alter their mating calls. J Comp Physiol A 188:799-805

Heinrich B (1993) The hot-blooded insects - strategies and mechanisms of thermoregulation. Springer, Berlin Heidelberg New York

Henaut A (1990) Study of the sound produced by Pimpla instigator (Hymenoptera, Ichneumonidae) during host selection. Entomophaga 35:127-139

Hoger U, French AS (1999) Temperature sensitivity of transduction and action potential conduction in a spider mechanoreceptor. Eur J Physiol 438:837-842

Hosler JS, Burns JE, Esch H (2000) Flight muscle resting potential and species-specific differences in chill-coma. J Insect Physiol 46:621-627

Hrncir M, Jarau S, Zucchi R, Barth FG (2004a) Thorax vibrations of a stingless bee (Melipona seminigra). I. No influence of visual flow. J Comp Physiol A 190:539-548

Hrncir M, Jarau S, Zucchi R, Barth FG (2004b) Thorax vibrations of a stingless bee (Melipona seminigra). II. Dependence on sugar concentration. J Comp Physiol A 190:549-560 
Hughes J, Hern A, Dorn S (2004) Preimaginal environment influences adult flight in Cydia molesta (Lepidoptera: Tortricidae). Environ Entomol 33:1155-1162

Kührt U, Samietz J, Dorn S (2005) Thermoregulation behaviour in codling moth larvae. Physiol Entomol 30:54-61

Martin SD, Gray DA, Cade WH (2000) Fine-scale temperature effects on cricket calling song. Can J Zool 78:706-712

Otten H, Wäckers F, Battini M, Dorn S (2001) Efficiency of vibrational sounding in the parasitoid Pimpla turionellae is affected by female size. Anim Behav 61:671-677

Otten H, Wäckers FL, Isidoro N, Romani R, Dorn S (2002) The subgenual organ in Pimpla turionellae L. (Hymenoptera: Ichneumonidae): Ultrastructure and behavioural evidence for its involvement in vibrational sounding. Redia 85:61-76

Pires A, Hoy RR (1992) Temperature coupling in cricket acoustic communication. 1. Field and laboratory studies of temperature effects on calling song production and recognition in Gryllus firmus. J Comp Physiol A 171:69-78

Reddy GVP, Holopainen JK, Guerrero A (2002) Olfactory responses of Plutella xylostella natural enemies to host pheromone, larval frass and green leaf cabbage volatiles. J Chem Ecol 28:131-143

Ritchie MG, Saarikettu M, Livingstone S, Hoikkala A (2001) Characterization of female preference functions for Drosophila montana courtship song and a test of the temperature coupling hypothesis. Evolution 55:721-727
Ryan MJ, Kime NM (2002) Signal-receiver coevolution. In: Simmons AM, Popper AN, Fay RR (eds) Acoustic communication. Springer, Berlin Heidelberg, New York, pp 246-255

Sanborn AF, Mate S (2000) Thermoregulation and the effect of body temperature on call temporal parameters in the cicada Diceroprocta olympusa (Homoptera: Cicadidae). Comp Biochem Physiol A 125:141-148

Shimizu I, Barth FG (1996) The effect of temperature on the temporal structure of the vibratory courtship signals of a spider (Cupiennius salei Keys). J Comp Physiol A 179:363-370

Stabentheiner A, Pressl H, Papst T, Hrassnigg N, Crailsheim K (2003) Endothermic heat production in honeybee winter clusters. J Exp Biol 206:353-358

Vallat A, Gu H, Dorn S (2005) How rainfall, relative humidity and temperature influence volatile emissions from apple trees in situ. Phytochemistry, doi: 10.1016/j.phytochem.2005.04.038

Wäckers FL, Mitter E, Dorn S (1998) Vibrational sounding by the pupal parasitoid Pimpla (Coccygomimus) turionellae: an additional solution to the reliability-detectability problem. Biol Control 11:141-146

Willmer PG, Stone GN, Johnston IA (2000) Environmental physiology of animals. Blackwell, London 